\title{
Entre ritmo e poesia: rap e literatura oral urbana
}

\author{
Marcus Rogério Salgado*
}

\begin{abstract}
RESUMO
O objetivo do presente artigo é fazer um estudo do rap enquanto manifestação de literatura oral urbana. Para tanto, o artigo passará em revista as relações entre literatura e palavra falada/cantada, assim como as possibilidades de interface estética entre a literatura e a música que estão em questão quando tratamos do rap.

Palavras-chave: Literatura oral urbana. Rap. Poéticas da voz.
\end{abstract}

Considerado um dos elementos definidores da cultura hip-hop, juntamente com o grafite e a dança, o rap é uma linguagem intermidial para a qual convergem elementos não apenas da música, como também de outras linguagens e modos de expressão. Isso fica explícito em seu próprio nome, pois rap significa rhythm and poetry - portanto, ritmo e poesia -, numa alusão à síntese de palavra e som que o caracteriza.

No código genético, o rap traz um regime estético em que se entrelaçam som e palavra. Esse regime insere-se plenamente numa tradição cultural de matriz africana na qual se verifica a sobrevivência das formas orais de literatura. É nesse sentido que o rap se afirma como ponto de convergência entre inúmeras manifestações culturais africanas e afro-americanas nas quais esses dois elementos - som e palavra, ritmo e poesia - se articulam de forma a gerar canções, narrativas, poemas etc. É possível reivindicar, como seus antecedentes, o blues e o gospel, as canções de trabalho dos escravos, os pregões de rua dos "negros de ganho" e os vissungos. Nessas formas todas, encontram-se palavra e som a fim de comunicar mensagens de fundo social, pelos quais se delineiam os mecanismos de exclusão operantes sob as mais diversas máscaras, nos mais diversos tempos e espaços.

O rap pressupõe a intermidialidade - cruzamento entre música, poesia e performance - como elemento estruturante no próprio conceito de obra de arte.

No campo da música, embora privilegie a mensagem verbal na comunicação de conteúdos musicais, o rap tem a performance como suporte final - por meio

* Universidade Federal do Rio de Janeiro - UFRJ. 
de apresentações ao vivo - e como linguagem de base. É por ela que se afirma a materialidade poética do rap, enquanto linguagem diretamente ligada ao corpo e à presença física, particularmente a voz, desde sempre sopro e atma, ao mesmo tempo que abertura para a emergência de um outro na dobra do discurso.

Além disso, o rap apresenta notável intimidade com procedimentos estéticos que habitualmente são identificados como pertencentes ao repertório das vanguardas, como a montagem, a recombinação, a colagem e até mesmo a poesia sonora.

Musicalmente, o rap é um dos pontos de culminância do que se pode chamar de "afromodernidade sonora" (WEHELIYE, 2005, p. 19), que seria a marca registrada da "complexa interface da cultura negra moderna com tecnologias sonoras" (WEHELIYE, 2005, p. 19). Como afirma Christian Béthune, o rap foi

a primeira forma de expressão a utilizar de forma sistemática as técnicas de reprodução sonora as mais sofisticadas, não apenas para difundir suas produções, mas igualmente para elaborá-las, tanto em sua forma como em seu conteúdo. (BÉTHUNE, 2003, p. 9).

A partir da recombinação de materiais pré-existentes - registros sonoros dos mais diversos tempos e espaços que, deslocados de seus contextos originais, funcionam como matéria-prima para novas criações sonoras -, o rap encena, no plano estético, uma forma moderna de poética da recombinação, "inscrevendose no movimento de um processo de reprodução en abyme, que, pela prática da telescopagem histórica, do deslocamento simbólico e da trituração sonora, abala a autoridade dos modelos tomados em empréstimo" (BÉTHUNE, 2003, p. 10).

É igualmente possível detectar no rap um esforço de elaboração estética no tocante ao uso da linguagem verbal. À maneira de um poema de Kurt Schwitters, no aparelho fonoarticulatório de um rapper e sob os efeitos da mesa de mixagem do $D j$, um fonema pode ser estendido até deformar-se e cristalizar-se em som puro, numa poética do significante. Onomatopeias, efeitos rítmicos e rímicos, jogos de entonação e inflexão de voz e timbre são procedimentos habituais no que diz respeito à palavra não apenas no rap, como também em outras manifestações da cultura afro-americana, presentes desde sempre nos spirituals e nas canções de trabalho, no samba de partido alto e no vissungo. A verdade é que, embora articule procedimentos de manipulação fonética no sentido de uma poética da voz que pode associá-lo a determinadas práticas postas em circulação no âmbito da cultura eurocêntrica sob a rubrica de "vanguarda", o rap é "profundamente influenciado pela tradição oral da cultura africana" (BÉTHUNE, 2003, p. 48), já que seu fundamento é a "elaboração 
oral do pensamento" (BÉTHUNE, 2003, p. 51), característica de sociedades onde a escrita não se impõe como valor de referência absoluta, ao mesmo tempo que a oralidade abre a possibilidade de uma "escrita da voz". (BÉTHUNE, 2003, p. 52). A diferença, contudo, é que no rap estamos diante de uma oralidade armada de tecnologia; assim, "incorporando-se à tecnologia e apropriando-se de seus recursos, a oralidade ganha uma nova força" (BÉTHUNE, 2003, p. 56), que permite sua coexistência com a escrita sem a subordinação da primeira pela última. Sendo "a dimensão performativa de suas origens orais" (BÉTHUNE, 2003, p. 57) amplificada pelo aparato tecnológico da música eletrônica, "o discurso do rapper conquista, graças à técnica, a ubiquidade da forma escrita.” (BÉTHUNE, 2003, p. 57).

Oralidade, poesia e música convergem na experiência afro ao longo do século XX; essa convergência encontra-se nas obras de Sun Ra, Cecil Taylor, Cartola ou Nelson Cavaquinho. É aqui que o rap se revela um elo no interior de um processo em encadeamento a que Robin Kelley chama de "imaginação radical negra". Essa imaginação propugnada por Kelley seria alicerçada na ideia de uma "poética da luta e da experiência vivida" (KELLEY, 2002, p. 9), sendo, ainda, uma forma de resistência cultural encontrada por escritores, artistas e ativistas afro-americanos para lidar não apenas com questões estéticas, e sim com "as condições da vida diária, das opressões quotidianas, da sobrevivência.” (KELLEY, 2002, p. 11). Ao trazer à boca da cena simultaneamente a voz de uma específica subjetividade afro-americana - a voz individual de cada rapper, com seu lastro particular de experiências vividas, a partir das quais são elaborados seus textos - e a visão de mundo coletiva de uma determinada comunidade - o rapper como voz coletiva -, o rap se consolida como uma forma de agenciamento comunitário e de resistência cultural.

Embora ostente emaranhadas relações com o político e o mercadológico, setor rentável da indústria do entretenimento, que move consideráveis cifras nesse âmbito, o rap mantém-se, contudo, como uma linguagem que pode ser considerada uma extensão de algumas ideias em circulação desde os anos 60 entre os pensadores dos movimentos negros ao redor do mundo. Assim, a música - mesmo quando inserida numa trama intrincada de relações econômicas - manter-se-ia como "arma poderosa na luta pela libertação negra” (KELLEY, 2002, p. 11), mantendo-se, portanto, a superestrutura como um campo de batalha com regras autônomas e não completamente determinado ou planificável pela infraestrutura. Como frisa Kelley, "se a música frequentemente e de forma negativa espelhou a cultura mais ampla, ela, independentemente disso, ajudou a gerar orgulho de comunidade, desafiou o auto-ódio racial e construiu respeito próprio.” (KELLEY, 2002, p. 11). 
Para além de uma perspectiva puramente estética que pode vincular o rap a outras linguagens da era da reprodutibilidade técnica, já que, com as técnicas do sampling e da mixagem, é possível fazer música a partir de registros sonoros préexistentes, as letras das canções podem ser ouvidas como crônicas, nas quais é registrado o cotidiano nas comunidades periféricas.

No plano discursivo, as letras de rap tematizam, em sua esmagadora maioria, o problema da violência e sua representação, ambos diretamente ligados à experiência urbana nas metrópoles brasileiras. Nesse sentido, lidar esteticamente com a violência não é prerrogativa do rap, e sim tendência verificada também na literatura e no cinema. É imensa a quantidade de produtos culturais feitos no Brasil desde finais do século XX que, a partir de uma perspectiva mimética de tipo realista, "tematizam e dramatizam a espessura do espaço urbano, ou seja, as formas de violência que se manifestam nas cidades e as modalidades com que o fenômeno é representado.” (GOMES, 2012, p. 76). A violência, portanto, não deve ser lida aqui como causa, e sim como sintoma. Sua presença no discurso poético de um gênero como o rap reflete "a reiterada presença do ato violento nos discursos sociais" (GOMES, 2012, p. 74). As camadas discursivas encontradas nas letras de rap apontam para uma estética do trauma, vez que procuram representar experiências individuais ou coletivas ligadas à violência, quer no plano sistêmico, institucionalizado ou interpessoal. É claro que há também uma função terapêutica implícita no jogo de enunciação e de encenação do real como proposto pelo rap, afinal, enunciar o ato de violência satisfaz, em alguma medida, "à necessidade psicológica de sobrepujar o trauma, permitindo sua assimilação como experiência." (GOMES, 2012, p. 74).

Aqui fica claro como o rap se alinha com certas manifestações de um "novo realismo", tal como o detecta Karl-Erik Schollhammer na literatura e nas artes visuais do Brasil contemporâneo. Trata-se de uma tendência que "se expressa na vontade de alguns escritores e artistas de relacionarem sua literatura e arte com a realidade social e cultural em que emerge, trazendo esse contexto para dentro da obra, esteticamente" (SCHOLLHAMMER, 2012, p. 134), encarando a literatura e a arte, portanto, como uma experiência comunitária. Outras marcas identitárias desse novo realismo seriam a preocupação "com a denúncia e com a intervenção política" (SCHOLLHAMMER, 2012, p. 134) e certa "afetividade oral" (SCHOLLHAMMER, 2012, p. 134), que o tornam bastante compatível à aproximação do rap para o interior de seu território.

De fato, há no rap um esforço programático em relacionar forma estética e realidade social. No plano musical, a estética da recombinação preconizada pelo 
sample e pela mixagem se constrói a partir de uma organização tecnológica hiperrealista de toda uma gama de ruídos:

o uivo das sirenes, o estalo dos tiros, o estrondo das cenas de interpelação com suas vociferações, suas cavalgadas, suas cantadas de pneu - em suma, todo o leque de superposições sonoras (layering) tornados possíveis graças à tecnologia e a partir das quais não é tão óbvio separar o real do simulado - imergindo seus propósitos em um hiper-realismo cuja expressão confere ao mundo exterior uma consistência palpável. (BÉTHUNE, 2003, p. 58).

O efeito de verossimilhança é buscado não apenas na gama de samples utilizados - que vai de sirenes da polícia até notícias sangrentas de telejornais, ou, no caso dos Racionais MC's, no sample de uma narrativa televisiva de incidente ocorrido durante sua apresentação na Praça da Sé-, como também no plano verbal. A voz no rap se pretende enunciar "mergulhada no coração da ação" (BÉTHUNE, 2003, p. 59). É assim que ouvimos a narrativa frenética que Sabotage fez, em uma das faixas do álbum $\mathbf{O}$ rap é compromisso, sobre uma ação criminosa contra uma instituição bancária, na qual somos convidados a imaginar a cena a partir do ponto de vista vertiginoso de um de seus participantes:

Truta só selo no Itaú da rua Alba

Agência desossada, PM acionada,

Celular na mão do zé povinho virou uma arma

Que louco, sufoco, o malote tá com o troco, pipoco

Agora é cada um por si e Deus por todos

A meio corpo eu vejo um gordo enfiando bala

Pra ser mar claro parou de AR-15 aquela barca

Impressionante cena cinematográfica central de Santo Amaro

Brooklin sul, o tempo não para

Não tem desculpa, só tem disputa

(SABOTAGE, 2001).

Focada no sensível, como ocorre com o "novo realismo" em literatura, "a narrativa então é a representação documental desse real" (GOMES, 2012, p. 78). Essa demanda por "verdade", que, por sua vez, é a contrassenha de uma demanda pelo real, pode materializar-se sob formas múltiplas, indo da construção ficcional lastreada por observações empíricas de uma realidade social dada à autoficcionalização - como ocorria com o falecido rapper Sabotage -, deslizando por uma linha tênue entre realidade empírica e criação ficcional, entre biografia e autoficção, entre acontecimento e percepção. Aqui encontra-se, é importante não omitir, um dos nós conceituais mais problemáticos dentre as proposições 
estéticas do rap e do chamado "novo realismo": contendo elementos da crônica, do documentário e do relato autobiográfico, essa "demanda por verdade" pode, em alguns casos, gerar uma espécie de recusa ou negativa implícita do estatuto ficcional dessas criações, de forma a, nos casos de maior rentabilidade estética no trânsito entre texto e mise-en-scène sonora, resolver-se com os esforços em prol de “uma osmose do poético e do real." (BÉTHUNE, 2003, 59).

Por outro lado, ressalte-se que a mencionada afetividade oral, que o compatibiliza com o "novo realismo" da literatura e das artes visuais, também manifesta-se de forma representativa no rap, sendo mesmo um seu traço identitário enquanto literatura oral urbana, sobretudo pela abertura polifônica encontrada na linha de vozes. Sobre o palco ou em um álbum, ao ouvir RZO, por exemplo, o desempenho das vozes de Negra Lee, Helião e Sandrão ao longo das canções deixa claro que elas são projetadas a partir de distintos e sucessivos lugares de enunciação. A diferença ocorre mesmo no plano da performance e da caracterização de palco dos vocalistas. Assim também com os Racionais MC's, onde a caracterização das personagens nos moldes de uma construção ficcional é feita tanto por recursos performáticos como pela própria fala, já que o rapper "configura sua voz aos traços dos personagens que ele faz falar." (BÉTHUNE, 2003, p. 60).

Isso se dá pelo fato de que o rap não enuncia uma única voz: ele próprio funciona como um lugar de encontro entre as vozes mais diversas no plano da subjetividade, que, contudo, trazem à boca de cena sua condição social determinada pela classe de origem, gerando, com isso, o efeito de "comunidade", no sentido que confere ao termo Agamben (1993). Aqui fica claro como esse efeito de comunidade - da voz coletiva - é obtido não exatamente pela homogeneização das diferenças em prol de um diapasão comunal (periferia como conceito norteador), e, sim, muito mais, pela atenção à escuta das vozes outras e múltiplas que compõem a partilha do sensível (RANCIÈRE, 2005).

É sob os signos da organização polifônica do discurso e do efeito de comunidade que se estruturam álbuns como Cores e valores (2014), dos Racionais MC's, e Direto do campo de extermínio (2003), do grupo Facção Central.

No caso dos Racionais MC's, as narrativas em primeira pessoa vão trazendo ao proscênio as mais diversas vozes. Algumas são carregadas de uma dramaticidade que as distingue das demais, como ocorre em "A escolha que eu fiz", relato em primeira pessoa de um assalto que termina em tiroteio, hospital e prisão:

Foi a escolha que eu fiz

Agora o sangue que escorre

Não apaga, não é giz

Eu vacilei, não olhei 
Tinha um pé ali atrás no balcão

Quando enquadrei

Entrei suando, era a deixa

(RACIONAIS MC's, 2014).

Entre as descrições eletrizantes da tentativa de fuga e abatimento pelos seguranças e pela polícia, a voz principal faz reflexões sobre sua situação naquele momento, num entrechoque de dois planos narrativos, o do relato das circunstâncias que o conduziram ao presente estado e o do próprio presente estado:

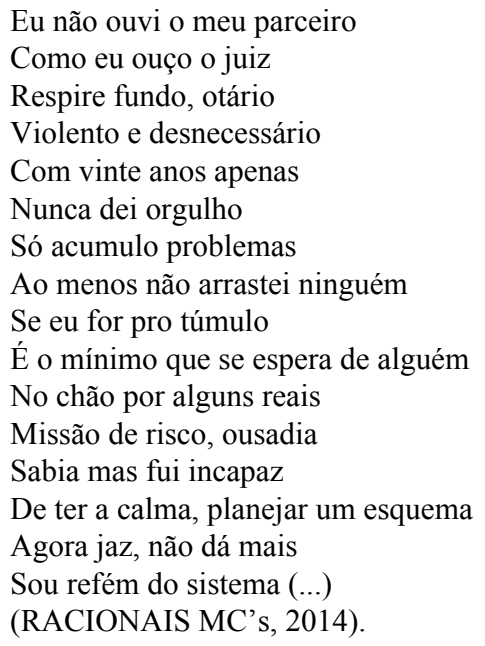

A voz do bandido que relata aquele que talvez seja seu último crime, vez que corre o risco de não sobreviver, encena um personagem que não é bidimensional, mostrando expressiva qualidade psicológica, para cujo êxito, em alguma medida, colabora o conhecimento experiencial, por parte do rapper, da realidade narrada em suas canções. Não se trata mais de uma elaboração ideológica feita a partir de um porta-voz detentor dos meios e modos de expressão da alta cultura letrada, e sim uma arqui-voz cujo lugar de enunciação coincide com o das vozes - a "comunidade" - que falam ao longo das canções. Por isso, talvez, a qualidade psicológica com que são representados certos tipos dessa comunidade, como, ainda em "A escolha que eu fiz", a percepção arguta de que o bandido, ainda que pré-programado para ser esmagado por uma máquina genocida, pactua com essa mesma sociedade do espetáculo, já que é ávido, também, por um reconhecimento vindo do "outro lado", ainda que um reconhecimento em negativo (o estigma), e um reconhecimento que o afaste de vez da memória da "comunidade": 
Cuspe na cara, chute, algema

Pior que bicho, lixo

Arrastado, mó cena

Se o Datena filmar

Se a minha estrela brilhar

Eu morro feliz

Vilão ou vagabundo

(RACIONAIS MC's, 2014)

Essa qualidade psicológica na composição das vozes/personagens é prova, de igual forma, de que, ao agenciar unidades formais da crônica, da collage e da montagem, o rap sinaliza, a sua maneira, para uma nova forma de realismo, justamente um realismo polifônico, para o qual convergem e se encontram as mais diversas vozes, numa arquitetura de ressonâncias.

Isso fica claro em Direto do campo de extermínio, da Facção Central. Os primeiros dez minutos do álbum são dedicados exclusivamente à palavra e a música propriamente dita só começa depois de que três blocos de experimentos verbais tomam lugar.

O primeiro deles é uma declaração de intenções do grupo, que passa por "informar os desinformados" e pela ação afirmativa do próprio rap, considerado como possibilidade de aquela "comunidade" viver economicamente a partir da produção de cultura. Vale lembrar que a ideia de que, de par com a redistribuição de renda, é necessária uma redistribuição da informação, em sociedades de código aberto, também está presente ao longo do álbum Traficando informação, de MVBill.

O segundo bloco verbal, intitulado "Vozes sem voz", apresenta as falas de moradores da "comunidade" que relatam, em primeira pessoa, as condições de exercício da cidadania a que estão submetidos. Na sequência de intervenções verbais de membros da comunidade é que se instaura o efeito polifônico em grau máximo, pois os relatos trazem à frente a voz dos próprios membros da comunidade, prescindindo temporariamente do porta-voz, na apresentação direta de suas demandas e interpelações à sociedade. O resultado estético é digno de nota: insere, na estrutura narrativa mais ampla do álbum, uma série de micronarrativas que se consumam e se consomem no espaço de sua duração. De qualquer forma, como sinaliza o título, entre as narrativas converge a ideia de vivência em um campo de extermínio. A periferia de São Paulo é comparada a uma Auschwitz, pré-programada para a morte em massa gerada pela violência institucionalizada. O habitante dessa "comunidade" é o homo sacer, para quem o direito foi temporariamente suspenso. Aqui vale notar como o rap permite a 
entrada em cena de um olhar documental, lançado sobre o complexo cultural híbrido que nos constitui socialmente.

O terceiro bloco é uma espécie de "canto falado", a capela, cuja inflexão remete aos spirituals dos afro-americanos; intitulado "Aqui ela não pode voar", nele desenvolve-se a imagem da capa do álbum, a de uma pomba ensanguentada, impossibilitada de voar:

\author{
No céu \\ Que a pólvora encobre as estrelas \\ Ela não pode voar \\ No chão \\ Minado contra os tiras e soldados \\ Ela não pode pousar \\ Suas asas estão manchadas de vermelho \\ Tem hematomas das correntes do cativeiro \\ O olhar, um rio de lágrimas, \\ Com navio de desespero \\ Na sua estrada \\ Estilhaços de granadas \\ Corpos entre quatro velas \\ Bala perdida da polícia \\ Outra criança morta na favela \\ (FACÇÃO CENTRAL, 2003)
}

O poder de síntese das imagens justapostas é notável. Com poucos signos, desenha-se um cenário (sub)urbano de traçantes riscando o céu, navios negreiros e instrumentos da escravidão, as minas, as balas perdidas e as granadas, na periferia de São Paulo ou em qualquer lugar revoltoso da África, vez que a pobreza étnica é fator determinante.

É nesse ponto que, com o eco da ideia norteadora de uma "imaginação radical negra" proposta por Kelley, faz-se necessário lembrar que o rap mantém uma estreita relação de referencialidade com a realidade de comunidades bem específicas, ao mesmo tempo em que se perfaz como linguagem híbrida panafricana, vez que tem suas raízes nas mais diversas práticas culturais de matriz africana, que foram plasmadas em sua criação. Para além de uma arqueologia mais remota das formas estéticas prefiguradoras do rap, vale lembrar que nele se encontram traços distinguíveis, a olho nu, de práticas culturais pertencentes a outros complexos culturais que não o dos Estados Unidos, local de seu nascimento oficial, como a cultura dos sistemas de som jamaicanos, cuja entrada em Nova Iorque está diretamente ligada aos fluxos migratórios - o que reforça os vínculos entre nomadismo e transmissão de culturas e textos orais. Mesmo o coletivo The 
Last Poets, que disputa com o DJ Kool Herc a primazia na definição, entre finais dos anos 60 e começo dos 70, de uma linguagem de ritmo e poesia precursora do que hoje conhecemos por rap, fazia uso de atabaques herdados diretamente da tradição musical e religiosa iorubá, baseada na ideia de obtenção de efeitos verbais pela música - a chamada "fala percussiva".

De igual forma, é importante registrar como o rap cruzou oceanos e multiplicouse em sotaques múltiplos: em língua portuguesa, temo-lo forte e vivo não apenas no Brasil, como também em Angola e Moçambique, e ainda em Portugal. O rap é, hoje, agente proeminente nos fluxos culturais que ligam a lusofonia. Como se percebe dos trânsitos sonoros contínuos realizados entre os diversos portos do Atlântico Negro, não é por acaso que o rap erigiu sua estética sonora a partir da mixagem de materiais gravados. Como frisa Weheliye,

ao tornar possível que audiências díspares numa variedade de lugares consumissem música negra, as tecnologias sonoras asseguraram que chamadas e respostas locais diferissem de acordo com as coordenadas espácio-temporais, facilitando a emergência e reconfiguração de numerosas práticas culturais. (WEHELIYE, 2005, p. 21).

Tais trânsitos garantiram, assim, uma dúplice articulação (pan-africano e local ao mesmo tempo) sonora e ideológica.

Entre nós, a influência do rap se faz não apenas no âmbito da música. Tirando proveito do fato de ser geneticamente dotado de potencialidades intermidiais, o rap tem deixado marcas significativas na produção textual da chamada literatura marginal/periférica. $\mathrm{O}$ caso mais notório é o de Ferréz. Como os rappers, o escritor paulistano é dotado de "uma percepção muito aguçada para recriar, no mundo ficcional, problemas e temas de sua realidade imediata" (SILVA, 2013, p. 630), pelo que, assim, "seu particular se torna universal, no momento em que a estória [sic] de Capão se torna uma história coletiva" (SILVA, 2013, p. 630). Além de estar apta a desdobrar essas duas instâncias a partir de dados imediatos da realidade empírica, a prosa de Ferréz contém marcas estilísticas que remetem ao fraseado rítmico característico da proclividade verbal dos rappers. Isso fica particularmente explícito em Ninguém é inocente em São Paulo (2006), cujos textos curtos se amparam de sobremaneira nos efeitos de oralidade e na modelagem rítmica da frase, como se percebe em "Terminal (nazista)", onde, para descrever o processo de desumanização sofrido pelas populações periféricas, causado pela precariedade do sistema de transporte coletivo, nem mesmo as rimas faltam: 
Olhei o letreiro, o destino era o mesmo.

Gente que ia cedo, gente que vinha tarde.

Gente que ia cedo, gente que vinha tarde.

Gente que ia cedo, gente que vinha tarde.

Voltei à fila, alguém me puxou, estava cortando, esqueci de avisar que ia

voltar.

Final da fila, tanto faz, sentado ou em pé, o gás é pra todos mesmo. (FERREZ, 2006, p. 90).

Capaz de desdobrar-se num projeto de resistência cultural mais amplo da matriz africana nas Américas e, ao mesmo tempo, fixar-se em problemas locais, o rap reafirma, em múltiplos planos, sua identidade híbrida. Ritmo e palavra, música e literatura oral, crônica e poema, autoficção e documentário, o rap se constitui, por conta desse hibridismo estruturante, em uma linguagem privilegiada para se tentar acesso pela via estética a um complexo cultural híbrido como as próprias cultura e sociedade brasileiras. Iniciativas como os saraus da Cooperifa (que se desdobraram numa miríade de eventos locados na periferia, tendo por temática a fusão entre palavra e som, como o Sarau Suburbano, o Sarau Ritmo e Poesia, o Sarau dos Mesquiteiros etc), editoras como a LiteraRua e a Literatura Marginal (para ficarmos em dois exemplos editoriais focalizados em literatura e distribuição marginais/periféricas), gravadoras como a Cosa Nostra e a Zâmbia ou ainda a tradução de obras da literatura marginal para outras línguas (como ocorre com o francês, pela editora Anacaona, que já traduziu Alessandro Buzo e Ferréz) mostram como a cultura hip-hop, na qual, como dito anteriormente, o rap se situa como o elemento estético sônico-verbal por excelência, constitui-se, além de instrumento cognitivo pelo qual se torna possível o acesso à cultura $\mathrm{e}$ à sociedade brasileira em suas dinâmicas mais profundas, também uma imagem possível de futuro para as populações das periferias, pois ele nos faz lembrar que a cultura "pertence àquele que é capaz de produzi-la" (FAUSTINO, 2002, p. 10) e que a força ilocutória da palavra se dá, também, no sentido de uma intervenção direta sobre o eixo-realidade, como se estivéssemos sempre prestes a mergulhar não mais no coração da ação, e, sim, no coração da história.

\begin{abstract}
The purpose of this article is to make a study of rap (rhythm and poetry) as a manifestation of urban oral literature. Therefore, it will review the relationship between literature and the spoken/sung
\end{abstract}


word, as well as the possibilities of aesthetical interface between literature and music that should necessarily be considered when theoretically or critically dealing with rap.

Keywords: Oral urban literature. Rap. Poetics of voice.

\section{Referências}

AGAMBEN, Giorgio. A comunidade que vem. Tradução de Antônio Guerreiro. Lisboa: Editorial Presença, 1993.

BÉTHUNE, Christian. Le Rap. Une esthétique hors la loi. Paris: Autrement, 2003. BILL, M. V. Traficando informação [CD]. Manaus: BMG. Digital, estéreo, 1999. FACÇÃO CENTRAL. Direto do campo de extermínio. [Fonograma]. Por Facção Central. Face da Morte Produções, 2003. CD.

FAUSTINO, Oswaldo. Das ruas ao coração. In: ROCHA, Janaína (Org.). HipHop: a periferia grita. São Paulo: Fundação Perseu Abramo, 2002.

FERREZ. Ninguém é inocente em São Paulo. Rio de Janeiro: Objetiva, 2006.

GOMES, Renato Cordeiro. Por um realismo brutal e cruel. In: GOMES, Renato C. (org.). Novos realismos. Belo Horizonte: Editora da UFMG, 2012.

KEELEY, Robin. Freedom dreams. The Black Radical Imagination. Boston: Beacon Press, 2002.

RACIONAIS MCs. Cores e valores. [Fonograma]. Por Racionais MCs. Cosa Nostra, 2014. CD.

RANCIÈRE, Jacques. A partilha do sensível: estética e política. Tradução de Mônica Costa Netto. São Paulo: EXO experimental org.; Ed. 34, 2005.

SABOTAGE. O rap é compromisso. [Fonograma]. Por Sabotage. Cosa Nostra, 2001. CD.

SCHOLLHAMMER, Karl Erik. "Do efeito ao afeto. Os caminhos do realismo performático". In: GOMES, Renato C. (Org.). Novos realismos. Belo Horizonte: Editora da UFMG, 2012.

SILVA, Mário Augusto Medeiros da. A descoberta do insólito. Literatura negra e literatura periférica no Brasil (1960-2000). Rio de Janeiro: Aeroplano, 2013.

TATE, Greg. Flyboy in the buttermilk. Essays on Contemporary America: an eye-opening look at race, politics, literature and music. New York: Simon \& Schuster, 1992. 
WEHELIYE, Alexander G. Phonographies. Grooves in Sonic Afro-Modernity. Durham: Duke University, 2005.

ZUMTHOR, Paul. A letra e a voz. São Paulo: Companhia das Letras, 1996.

ZUMTHOR, Paul. Introdução à poesia oral. Belo Horizonte: Editora da UFMG, 2010.

Submetido em: 15 de junho de 2015. Aceito para publicação em: 09 de outubro de 2015. 



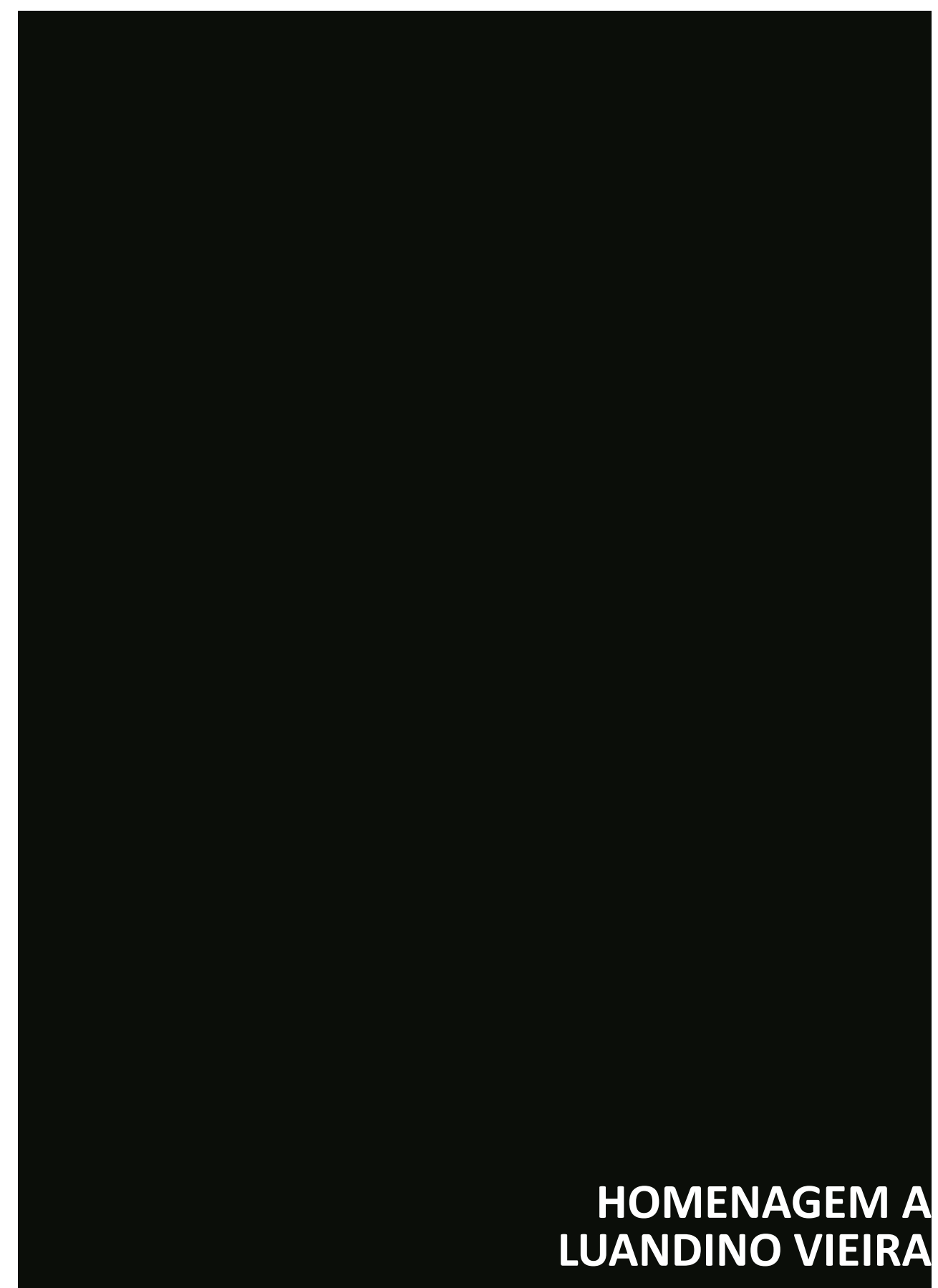


